\title{
Abnormal Redox Status of Membrane-Protein Thiols in Sickle Erythrocytes
}

\author{
Brian H. Rank, Jan Carlsson, and Robert P. Hebbel \\ Department of Medicine, University of Minnesota Medical School, Minneapolis, Minnesota 55455
}

\begin{abstract}
Although sickle erythrocytes (RBC) undergo excessive autooxidation, investigators have not found evidence for abnormal oxidation of protein thiols in sickle RBC membranes (e.g., protein aggregates linked by intermolecular disulfide bonds). However, the conventional techniques heretofore used cannot detect more subtle changes in thiol status such as abnormal intramolecular disulfide bonds. We examined RBC membranes using thiol-disulfide exchange chromatography which partitions sodium dodecyl sulfate-solubilized proteins on the basis of reactive thiols, yielding gel-bound (reduced-thiol) and filtrate (oxidized/blocked-thiol) fractions. Membranes from normal RBC partition so that only $13.6 \pm 1.4 \%$ of all membrane protein is found in the filtrate fraction. An abnormally increased amount of membrane protein from sickle RBC (21.5 $\pm 4.3 \%)$ partitions into the filtrate fraction $(P<0.001)$. Since sickle RBC do not have high molecular weight aggregates of membrane protein, this indicates abnormal intramolecular thiol oxidation in sickle RBC membranes. Treatment of normal RBC with thiol blockers and oxidants simulates this shift of membrane protein into the filtrate fraction. Analysis using polyacrylamide gel electrophoresis reveals that the filtrate fraction derived from normal RBC consists mostly of band 7 and glycophorins, with only trace amounts of other membrane proteins. Superimposed upon this normal background, sickle RBC filtrates are enriched with all proteins (including cytoskeletal protein bands 1, 2, 2.1, and 4.1), suggesting a generalized oxidative perturbation of sickle RBC membranes. These observations support the concept that excessive $R B C$ autooxidation may play a role in sickle disease pathophysiology, and they perhaps help explain the development of those membrane abnormalities that may reflect cytoskeletal dysfunction in sickle erythrocytes.
\end{abstract}

\section{Introduction}

The functional integrity of the erythrocyte $(\mathrm{RBC})^{1}$ membrane undoubtedly requires normal interactions between cytoskeletal

This study previously appeared in preliminary form in 1983 in Blood. 62:60a.

Address reprint requests to Dr. Hebbel, Box 480, Mayo Building, 420 Delaware St., S.E., Minneapolis, MN 55455.

Received for publication 21 February 1984 and in revised form 15 January 1985.

1. Abbreviations used in this paper: BME, beta-mercaptoethanol; DTP, 2,2 dithiodipyridine; DTT, dithiothreitol; Hct, hematocrit; HMW, high molecular weight; MMTS, methylmethane-thiosulfonate; NEM, $N$ ethylmaleimide; PAS, periodic acid-Schiff (stain); PAGE, polyacrylamide gel electrophoresis; PMSF, phenylmethylsulfonylfluoride; RBC, erythrocyte(s).

J. Clin. Invest.

(C) The American Society for Clinical Investigation, Inc.

0021-9738/85/05/1531/07 \$1.00

Volume 75, May 1985, 1531-1537 proteins (1). In turn, these interactions appear to depend, in part, upon preservation of cytoskeletal protein thiols in their optimal redox state. For example, the thiol-reactive reagent $N$-ethylmaleimide (NEM) adversely affects spectrin self-association (2) and spectrin interactions with band 2.1 (3) and 4.1 (4) membrane proteins. Furthermore, the attenuated RBC survival associated with hemoglobin Köln (5), diamide treatment (6), and certain glucose-6-phosphate dehydrogenasedeficient variants (7) is associated with appearance of high molecular weight (HMW) aggregates of membrane proteins linked by intermolecular disulfide bonds. Their presence is believed to reflect participation of oxidative processes in the pathophysiology of these disorders.

We suspected that sickle RBC membrane proteins also might acquire abnormalities of thiol redox status, since sickle RBC spontaneously generate approximately twice the normal amounts of activated oxygen species (8). Although investigators have been unable to detect HMW protein aggregates in sickle RBC membranes (1), the conventional techniques heretofore applied to analysis of sickle RBC cannot detect more subtle (i.e., intramolecular) changes in thiol status. Consequently, we used thiol-dependent partitioning of sodium dodecyl sulfate (SDS)-solubilized membrane proteins (using thiol-disulfide exchange chromatography) to evaluate thiol redox status of membranes from normal, oxidant-treated, and sickle RBC.

\section{Methods}

\section{Materials}

SDS for all procedures was obtained from BDH Chemicals Ltd., Poole, England. Thiol-activated Sepharose 4B and $2.5 \mathrm{ml}$ Sephadex G-25 (PD-10) columns were obtained from Pharmacia Fine Chemicals, Div. of Pharmacia Inc., Piscataway, NJ. $\left[{ }^{14} \mathrm{C}\right]$ iodoacetamide $(53 \mathrm{mCi} / \mathrm{mmol})$ was obtained from Amersham Corp., Arlington Heights, IL. Cronex film was obtained from Kodak, and Enhance was obtained from New England Nuclear, Boston, MA. All other reagents were obtained from Sigma Chemical Co., St. Louis, MO.

\section{Membrane preparation}

Fresh citrated or heparinized blood was obtained from normal adults, sickle cell anemia patients, and individuals with other hemolytic disorders. RBC were washed three times in isotonic saline with removal of the buffy coat, and RBC membranes were prepared by hypotonic lysis and five washes in $20 \mathrm{vol}$ of degassed, ice-cold 5-mM sodium phosphate buffer (pH 8.0) containing $100 \mathrm{mg} /$ liter PMSF (phenylmethylsulfonylfluoride) and $0.1 \mathrm{mM}$ EDTA. RBC membranes were solubilized by addition of $1 / 9$ th vol of $20 \%$ SDS followed by boiling for 5 min and were immediately applied to the thiol-disulfide exchange chromatography assay (see below).

\section{$R B C$ manipulations}

For some experiments, washed $\mathrm{RBC}$ were incubated at hematocrit (Hct) $10 \%$ in phosphate-buffered saline (PBS) containing $5 \mathrm{mM}$ diamide for $30 \mathrm{~min}$ at $37^{\circ} \mathrm{C}$. They were then washed four times in saline and reincubated for $30 \mathrm{~min}$ in PBS with or without $10 \mathrm{mM}$ 
dithiothreitol (DTT). After additional saline washes, membranes were prepared as above. In other experiments, fresh normal or sickle $\mathrm{RBC}$ were incubated $\left(30 \mathrm{~min}\right.$ at $\left.37^{\circ} \mathrm{C}\right)$ at $\mathrm{Hct} 10 \%$ in PBS with $10 \mathrm{mM}$ DTT.

For exposure to the thiol-blocking reagent methylmethane-thiosulfonate (MMTS), normal RBC membranes prepared as above were incubated for $2 \mathrm{~h}$ at room temperature in Tris-buffered saline $(\mathrm{pH} 7.4)$ with or without $25 \mathrm{mM}$ MMTS. Membranes were then washed three times in $5 \mathrm{mM}$ sodium phosphate buffer (pH 7.4) and solubilized in SDS.

For exposure to activated oxygen, RBC were suspended to Hct $10 \%$ in Hanks' balanced salt solution containing $5 \mathrm{mM}$ glucose, $5 \mathrm{mM}$ acetaldehyde, $2 \mathrm{mM} \mathrm{FeCl} / \mathrm{EDTA}$, and $1 \mathrm{U} / \mathrm{ml}$ each of glucose oxidase and xanthine oxidase. After a $1-\mathrm{h}$ incubation at $37^{\circ} \mathrm{C}, \mathrm{RBC}$ were washed three times with saline, and membranes were prepared as above. Control RBC were incubated with all reagents except enzymes.

\section{Thiol-disulfide exchange chromatography}

Theoretical versus practical aspects. Solubilized membranes may be considered to consist of three types of proteins: those with reduced thiols (PSH), those with no thiols (P), and those with blocked/oxidized thiols (PSX). Upon exposure to thiol-activated agarose gel (agarose containing 2-pyridyl-disulfide groups), PSH proteins bind to the gel (and can later be released with beta-mercaptoethanol [BME]), while $P$ and PSX proteins are found in the filtrate fraction. An increase in filtrate protein, therefore, reflects abnormally increased thiol blockage/ oxidation.

Precise conditions used here are those required for optimal gelbinding of RBC membrane proteins as determined by preliminary experiments that were based upon prior applications of this technique to other proteins (9). The theoretical capacity of the gel $(1 \mu \mathrm{mol} / \mathrm{ml}$ of swollen gel) is such that the gel/membrane ratio we used $(3 \mathrm{ml}$ gel for a maximum of $5 \mathrm{mg}$ protein) should provide at least a 10-fold excess binding capacity (assuming $60 \mathrm{nmol}$ reduced thiol/mg membrane protein). However, as determined by our preliminary studies, the practical capacity of thiol-activated agarose is considerably less than this, and the amount of gel used was calculated to provide at least a $50 \%$ excess of 2-pyridyl-disulfide groups over the practical capacity of the gel for normal RBC membranes prepared as above. This was experimentally verified by determining that an increase in the amount of gel used did not alter the percent of gel-bound protein (data not shown).

Performance of the assay. Thiol-activated Sepharose 4B was swollen and washed in a sintered-glass funnel with "gel-buffer" $(0.2 \mathrm{M} \mathrm{NaCl}$; $0.2 \mathrm{M}$ sodium phosphate; $2 \% \mathrm{SDS} ; 100 \mathrm{mg} /$ liter PMSF; and $0.1 \mathrm{mM}$ EDTA, pH 8.4, degassed). This gel was suctioned to semidryness, and $3.0 \mathrm{~g}$ of gel was placed into a 10-cc plastic column with a sinteredglass filter bottom. $1 \mathrm{ml}$ gel-buffer and $1.0 \mathrm{ml}$ SDS-solubilized membranes (2-5 $\mathrm{mg}$ protein $/ \mathrm{ml}$ ) were then added, and the columns were tightly capped after equilibration with $100 \% \mathrm{~N}_{2}$. After gentle agitation in an $\mathrm{N}_{2}$ atmosphere for $15 \mathrm{~h}$ at room temperature, columns were allowed to drain, and the filtrate was collected. This volume was pooled with that derived from a brief additional $3.0-\mathrm{ml}$ gel-buffer wash and saved as "filtrate" (the blocked/oxidized-thiol) fraction.

The gel was then washed with $30 \mathrm{ml}$ "wash-buffer" $(5 \mathrm{mM}$ sodium phosphate; $2 \%$ SDS; $100 \mathrm{mg} /$ liter PMSF; and $0.1 \mathrm{mM}$ EDTA, pH 8.4), which was then discarded. Gel-bound proteins were released by addition of $1.0 \mathrm{ml}$ wash-buffer and $200 \mu \mathrm{l}$ of BME, after which the gel was gently agitated for $1 \mathrm{~h}$ at room temperature. After drainage of the column, this step was repeated once more and was followed by a brief additional 3.0-ml wash with wash-buffer. These pooled washes were saved as "gel-bound" (reduced-thiol) fraction.

For removal of BME (from the gel-bound fraction) and lowering of salt concentration (in the filtrate fraction) and/or for sample concentration, samples were dialyzed (exclusion limit $=1,200 \mathrm{D}$ ) against $0.01 \%$ SDS containing $10 \mathrm{mg} / \mathrm{liter}$ PMSF and $10 \mu \mathrm{M}$ EDTA and then lyophylized. An alternative approach, used to remove BME when sample concentration was not required, was passage of samples through a 2.5-ml Sephadex G-25 column.

Comments regarding the technique. Although thiol-activated Sepharose 4B theoretically can be regenerated and reused, we have found that efficiency of regeneration is unacceptably inconstant. All studies reported here were performed with new, unused gel. All analyses were done in duplicate, and the technique was found to be highly reproducible, with replicate results generally being within $1 \%$ of each other. Also, recovery was quantitative, with amount of protein in $4 B$ filtrate plus $4 \mathrm{~B}$ gel-bound fractions being within $\pm 4 \%$ of total amount applied to the column.

Performance of this technique as described here appears to provide adequate protection against potential artifactual oxidation of membrane proteins during preparative steps. More extensive precautions (virtually all steps performed in $100 \% \mathrm{~N}_{2}$ atmosphere and using $\mathrm{N}_{2}$-saturated buffers) did not alter results at all (data not shown).

Our standard conditions included use of PMSF and EDTA as protease inhibitors during all steps in the procedure. Although failure to employ protease inhibitors did not alter quantitative results of the thiol-disulfide chromatography assay (data not shown), the resulting polyacrylamide gel electrophoresis (PAGE) gels are difficult to interpret due to extensive proteolysis. The additional employment of sulfhydryl protease inhibitors $(0.1 \mathrm{mM}$ leupeptin or $20 \mu \mathrm{M}$ Ep475) had no additional beneficial effect upon quantitative or qualitative results, nor did use of higher concentrations of the various inhibitors (data not shown).

Nonspecific binding of proteins to the agarose gel was not a problem. For example, if filtrate protein was reapplied to fresh gel, $100 \%$ again appeared in the filtrate; and if the gel's 2-pyridyl-disulfide groups were completely removed with reducing agents, $100 \%$ of applied membrane protein appeared in the filtrate (data not shown).

\section{Protein determinations}

Protein concentrations of the various fractions were determined by the method of Lowry et al. (10).

\section{PAGE}

Aliquots of original membrane preparations and the dialyzed and concentrated filtrate and gel-bound fractions were diluted to $2 \mathrm{mg} / \mathrm{ml}$ with wash-buffer. They were then diluted 1:1 (with buffer containing $15.6 \%$ glycerol; $0.86 \mathrm{M}$ BME; $5 \%$ SDS; and $0.125 \mathrm{M}$ Tris $\mathrm{HCl}, \mathrm{pH}$ $6.8)$ and boiled for $5 \mathrm{~min}$. Equal amounts of protein $(10 \mu \mathrm{g})$ were applied to each lane on gradient $(7.5-15.0 \%)$ polyacrylamide slab gels, which were then run according to the method of Laemmli (11) and stained with Coomassie blue or periodic acid-Schiff (PAS).

\section{Thiol titration}

Reduced thiol concentrations were determined by titration of proteins with 2,2 dithiodipyridine (DTP) (12). After dilution of original membranes and gel-bound proteins and after concentration of filtrate fractions to $1 \mathrm{mg}$ protein in $0.85 \mathrm{ml}$ wash-buffer (containing $2 \% \mathrm{SDS}$ ), preparations were boiled for $5 \mathrm{~min}, 0.15 \mathrm{ml}$ of $1.5 \mathrm{mM}$ DTP was added, and absorbance at $343 \mathrm{~nm}$ was measured against appropriate blanks. Concentration of DTP-titratable thiols was calculated from the molar extinction coefficient of the reaction product 2-thiopyridone $\left(\epsilon_{\mathrm{m}}\right.$ $=8.08 \times 10^{3} \mathrm{M}^{-1} \mathrm{~cm}^{-1}$ [12]). Such results corresponded well with calculation of results from a standard curve derived from similar treatment of $0.5-100 \mathrm{nmol} / \mathrm{ml}$ glutathione. The sensitivity of this technique is such that we could detect $1 \mathrm{nmol}$ reduced thiol/mg protein ( $\sim 2 \%$ of the total titratable thiols of normal RBC membrane proteins). Results of thiol titrations were identical using 5,5'-dithiobis(2nitrobenzoic acid) (DTNB), a somewhat more sensitive titrating agent $\left(\epsilon_{\mathrm{m}}=1.36 \times 10^{4} \mathrm{M}^{-1} \mathrm{~cm}^{-1}\right)$.

Since filtrate fractions always have zero detectable reduced thiols (see below), we also attempted to document existence of residual reduced thiols in these fractions by incubating $100 \mu \mathrm{g}$ boiled protein (at $2 \mathrm{mg} / \mathrm{ml}$ in "wash buffer") for $15 \mathrm{~h}$ at $4^{\circ} \mathrm{C}$ with $0.25 \mu \mathrm{Ci}$ 
$\left[{ }^{14} \mathrm{C}\right]$ iodoacetamide. Samples were then applied directly to PAGE as above. PAGE slabs were soaked in Enhance and dried, and autoradiographs were obtained using Cronex film and a 5-d exposure time.

\section{Statistical analysis}

Statistical analysis employed $t$ test.

\section{Results}

Quantitative aspects of partitioning. Membranes from normal RBC partitioned so that most proteins bound to the thiolactivated agarose gel, and only $13.6 \pm 1.4 \%(n=10)$ of the original protein was found in the filtrate (oxidized/blockedthiol) fraction (Table I). In contrast, an abnormally large proportion of membrane protein from sickle RBC partitioned into the filtrate fraction $(21.5 \pm 4.3 \%[n=10])$. This significant increase $(P<0.001)$ represents an average increment of $\sim 8 \%$ superimposed on the amount of filtrate protein from normal RBC, but the degree of this abnormality varied considerably among sickle patients; individual values are listed in a footnote to Table I.

Excessive partitioning of membrane protein into the filtrate fraction was simulated by treatment of normal RBC with thiol blockers or oxidants (MMTS, diamide, and enzymatically generated oxygen radicals). For example, incubation with diamide induced an increase in filtrate protein, and this shift was not observed when the diamide-treated RBC were reincubated with DTT before partitioning assay (Table I).

Analogous pretreatment of fresh (unmanipulated) RBC with DTT diminished the amount of protein partitioning into the filtrate very slightly for normal $\mathrm{RBC}$ and had a variable effect upon sickle RBC (Table II). Partitioning of RBC membrane proteins from one patient who underwent exchange transfusion was nearly normal immediately after exchange, but over 6 wk reverted towards the patient's highly oxidized baseline state (data not shown).

The partitioning abnormality of sickle RBC membrane proteins is not explained simply by reticulocytosis. Analysis of high-retic control patients (Table III) revealed that not all

Table I. Thiol-dependent Partitioning of SDS-solubilized RBC Membranes Using Thiol-Disulfide Exchange Chromatography*

\begin{tabular}{|c|c|c|c|c|}
\hline & \multicolumn{4}{|c|}{$\begin{array}{l}\text { Percent of membrane protein partitioning } \\
\text { into the filtrate fraction }\end{array}$} \\
\hline & $N$ & Mean \pm SD & Range & $P$ \\
\hline Normal RBC $\ddagger$ & 10 & $13.6 \pm 1.4$ & $11.5-15.9$ & 一 \\
\hline Sickle RBC§ & 10 & $21.5 \pm 4.3$ & $15.9-28.4$ & $\|$ \\
\hline \multicolumn{5}{|l|}{ Manipulated normal RBC } \\
\hline Control incubations & 4 & $14.6 \pm 1.5$ & $13.1-15.9$ & - \\
\hline MMTS-treated (25 mM) & 3 & $85.0 \pm 3.9$ & $80.9-88.7$ & I \\
\hline Oxygen radical exposure & 3 & $25.7 \pm 0.9$ & $24.8-26.6$ & I \\
\hline Diamide-treated (5 mM) & 4 & $25.9 \pm 2.8$ & $23.0-28.9$ & I \\
\hline \multicolumn{5}{|l|}{ Diamide followed by } \\
\hline DTT & 3 & $13.4 \pm 0.7$ & $12.7-14.1$ & - \\
\hline
\end{tabular}

* SDS-solubilized RBC membranes were boiled and admixed with thiol-activated agarose under conditions for optimal protein binding to the gel (see Methods). Proteins lacking reduced thiols partitioned into the filtrate fraction, an increase of which reflected abnormal thiol blockage/oxidation.

$\ddagger$ Individual values are $11.5,11.9,12.7,13.2,13.3,13.9,14.3,14.4,15.1$, and 15.9.

$\S$ Individual values are $15.9,16.6,17.7,19.5,19.7,22.3,24.1,24.9,26.3$, and

28.4 .

" Differs from normal by $P<0.001$

I Differs from control incubations by $P<0.001$.
Table II. Effect of RBC Pretreatment with DTT upon Amount of Protein Subsequently Partitioning into the Filtrate Fraction*

\begin{tabular}{cll}
\hline & \multicolumn{2}{l}{$\begin{array}{l}\text { Percent of membrane protein partitioning } \\
\text { into the filtrate fraction }\end{array}$} \\
\cline { 2 - 3 } Patients & Without DTT pretreatment & With DTT pretreatment \\
\hline Normal & & \\
1 & 13.9 & 12.6 \\
2 & 14.4 & 13.7 \\
3 & 15.1 & 13.6 \\
4 & 15.9 & 14.5 \\
Sickle & & \\
1 & 21.5 & 17.5 \\
2 & 24.2 & 18.2 \\
3 & 25.0 & 19.3 \\
4 & 28.2 & 27.6 \\
\hline
\end{tabular}

* Thiol-dependent partitioning of SDS-solubilized RBC membrane proteins was determined (per Table I) on four normal and four sickle patients. RBC were compared with and without pretreatment using $10 \mathrm{mM}$ DTT before preparation of membranes and performance of thiol-disulfide exchange chromatography assay.

hemolytic disorders were associated with increased amounts of filtrate protein. Rather, only those putatively oxidative hemolytic disorders (i.e., unstable hemoglobinopathy or oxidant susceptibility) had increased amounts of filtrate protein.

Qualitative aspects of partitioning. Analysis of RBC membranes and their filtrate and gel-bound fractions using slab

Table III. Analysis of High Reticulocyte Control Patients Using Thiol-Disulfide Exchange Chromatography*

\begin{tabular}{ll}
\hline Reticulocyte & $\begin{array}{l}\text { Percent of membrane } \\
\text { protein partitioning into } \\
\text { the filtrate fraction }\end{array}$ \\
\hline$\%$ &
\end{tabular}

Nonoxidative high retic states

Repletion of folate deficiency

Repletion of iron deficiency

Paroxysmal nocturnal hemoglobinuria

Pyrimidine-5'-nucleotidase deficiency

Putatively oxidative hemolytic states

G6PD deficiency (A-type)

G6PD deficiency

(Caucasian variant)

$\mathrm{Hb} \mathrm{S/C}$

Hb Köln

$\mathrm{Hb} \mathrm{E} / \beta$ thalassemia
25

6

20

8
11.0
14.1
19.8
16.6
21.4
25.5
34.2

20
* SDS-solubilized RBC membranes were assayed using thiol-disulfide exchange chromatography per Table I. One patient with each disorder was available for analysis, and each was assayed in parallel with a normal control. Partitioning values for all normal controls were within the previously stated normal range (11.5-15.9\% of protein in the filtrate fraction). G6PD, glucose-6-phosphate dehydrogenase. 
gradient-PAGE stained with Coomassie blue is shown in Fig. 1. To facilitate comparison of normal membranes with normal and sickle filtrate fractions, Fig. 2 shows densitometry tracings of these three preparations.

In striking contrast to the PAGE pattern of normal RBC membranes (Fig. 1, lane 1), the normal filtrate fraction (lane 2) consisted mostly of two major proteins: band 7 and a protein migrating just above band 4.1. The latter protein appears to be glycophorin since it stained intensely with PAS; indeed, all PAS-staining proteins partitioned completely into the filtrate fraction (data not shown). In addition to band 7 and glycophorin, the normal filtrate contained trace amounts of several other membrane proteins.

The gel-bound fraction from normal RBC membranes (Fig. 1, lane 3), having been depleted of the filtrate fraction proteins (which compose $\sim 13 \%$ of total membrane protein), shows the expected reciprocal changes. For example, band 7 partitioned completely into the filtrate fraction and is, therefore, missing from the gel-bound lane. Unfortunately, the shift of glycophorin is not as readily discernible since it stained relatively

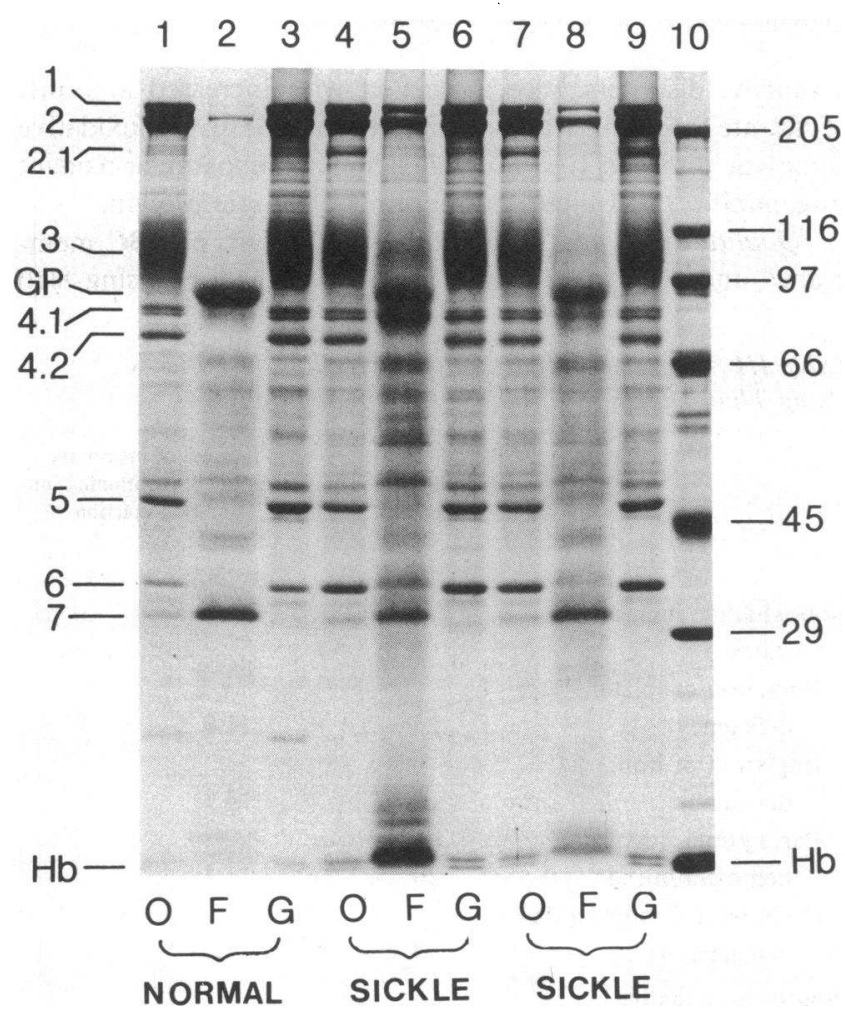

Figure 1. Qualitative analysis of RBC membrane proteins previously subjected to partitioning analysis using thiol-disulfide exchange chromatography. Each lane of this $7.5-15 \%$ gradient PAGE carries $10 \mu \mathrm{g}$ protein, and the slab has been stained with Coomassie blue. Major protein bands are indicated to the left of the normal RBC membranes in lane 1. GP, glycophorin; 2.1, highest molecular weight 2.1 family proteins. Molecular weight standards are carried in lane 10 , with weights (in $\mathrm{kD}$ ) at the right. Lanes 1-3 carry membrane proteins from normal RBC; lanes 4-6 carry those from a sickle patient with 28.4\% partitioning into the filtrate fraction; lanes 7-9 carry those from a sickle patient with $22.3 \%$ in the filtrate fraction. Lanes carry either original unpartitioned membranes $(\mathrm{O})$, filtrate fractions $(\mathrm{F})$, or gel-bound proteins $(G)$.

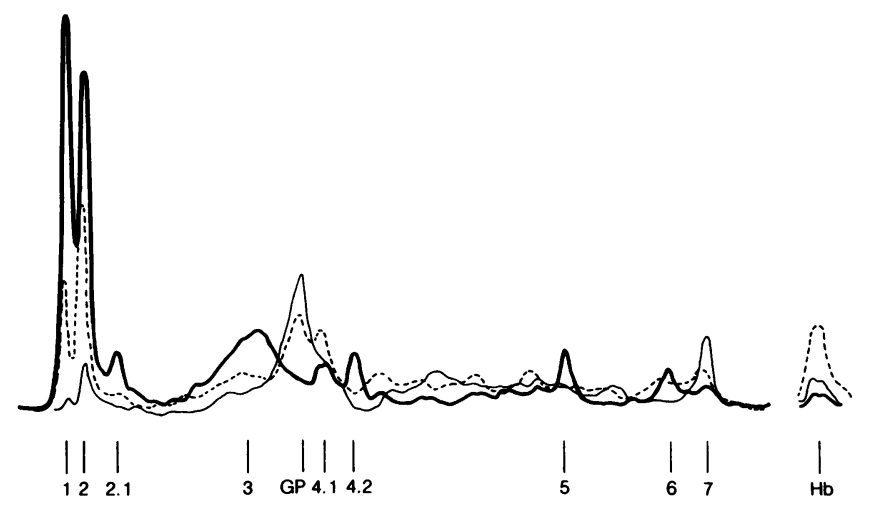

Figure 2. Artist's tracing of densitometry scans from a slab PAGE similar to that shown in Fig. 1. Illustrated here are normal RBC membranes (thick line), filtrate fractions derived from normal RBC (thin line), and sickle RBC (broken line). These are comparable to lanes 1, 2, and 5 in Fig. 1, respectively. The normal RBC filtrate consists mostly of glycophorin (GP) and band 7, with trace amounts of other membrane proteins (but no demonstrable band 2.1). Sickle filtrates contain less GP and band 7, since these were diluted out by the abnormal presence of other membrane proteins. Of particular interest, major cytoskeletal proteins (bands 1, 2, 2.1 family, and 4.1) are clearly found in excess in the sickle filtrates.

poorly with Coomassie blue (and is seen well in lane 2 because it is present in such high concentration). However, since all lanes in Fig. 1 carry the same amount of protein, the depletion of filtrate proteins resulted in a somewhat greater staining intensity for most bands in the gel-bound lane (lane 3) compared with the original membrane preparation (lane 1).

In contrast to the rather limited composition of the normal RBC filtrate fraction (Fig. 1, lane 2), the filtrate fractions derived from sickle $\mathrm{RBC}$ were markedly abnormal. Lanes 4-6 carry samples from a sickle patient with $28.4 \%$ of protein in the filtrate, and lanes 7-9 carry samples from a sickle patient with $22.3 \%$ of protein in the filtrate. The sickle filtrate fractions (lanes 5 and 8 ) reveal a general enrichment of all membrane components compared with the normal filtrate fraction in lane 2 . Since normal components of the filtrate fraction (i.e., band 7 and glycophorin) were relatively diluted by the abnormal presence of other proteins in the sickle filtrate, amounts of band 7 and glycophorin were reduced in the sickle filtrate compared with the normal filtrate; this is readily apparent in Fig. 2.

Of particular interest, the filtrate from sickle RBC (e.g., lane 5) contained markedly increased amounts of membrane cytoskeletal proteins: spectrin (bands 1 and 2), band 4.1 proteins, and ankyrin. The latter protein (band 2.1) in the sickle filtrates was less than optimally apparent, in part because this protein appeared to be particularly susceptible to the apparently unavoidable proteolysis that occurred during the many preparative steps in this assay. Consequently, many protein bands between band 2 and 3 in the sickle filtrates represent proteolytic fragments of band 2.1 (13). Indeed, the designation " 2.1 " in Figs. 1 and 2 is used here to indicate the highest molecular weight 2.1 -related proteins in these preparations. However, we have also demonstrated band 2.1 itself in sickle (but not normal) filtrate fractions applied directly to Fairbanks tube gels (thereby avoiding the prolonged processing 
required for desalting and sample concentration; data not shown).

Sickle RBC membranes had no HMW aggregates, either in the $3 \%$ stacking gels on Laemmli slabs or on $4 \%$ Fairbanks tube gels run without reducing agents (data not shown), as previously reported (1). It is apparent that sickle membranes carried increased amounts of hemoglobin (Fig. 1) and that sickle filtrate fractions contained a significant amount of hemoglobin (Figs. 1 and 2).

Thiol titration. Titration of protein thiols with DTP revealed unfractionated normal RBC membranes to have $60.3 \pm 9.2$ $\mathrm{nmol}(n=10)$ reduced thiol/mg protein (consistent with the existing literature reviewed in reference 14 ), while sickle RBC membranes have $48.1 \pm 9.1 \mathrm{nmol}$ reduced thiol/mg protein $(n$ $=8$ ). DTP titration failed to detect any reduced thiols in filtrate fractions from either normal or sickle RBC $(0 \pm 0 \mathrm{nmol} /$ mg; $n=7$ each). Identical results were obtained using 5,5'dithiobis(2-nitrobenzoic acid) for analysis of filtrate proteins. Similarly, presence of residual reduced thiols in filtrate fractions could not be detected using labeling with $\left[{ }^{14} \mathrm{C}\right]$ iodoacetamide and autoradiography (Fig. 3).

Treatment of filtrate proteins with DTT. As discussed below, most filtrate protein derived from normal RBC lacked constituent thiol groups. In contrast, much sickle filtrate protein had oxidized/blocked thiols. Therefore, treatment of these filtrate fractions with thiol-reducing agents would have been expected to expose a greater number of newly reduced thiols in sickle filtrates than in normal filtrates. Consequently, we treated filtrate fractions with $10 \mathrm{mM}$ DTT (followed by dialysis to remove DTT). As expected, DTT treatment of filtrate fractions (which started with zero titratable thiols) exposed more thiols in sickle filtrates $(24.1 \pm 11.1 \mathrm{nmol} / \mathrm{mg} ; n$ $=3$ ) than in normal filtrates $(12.6 \pm 4.6 \mathrm{nmol} / \mathrm{mg} ; n=3)$. Consistent with this, reapplication of these treated filtrates to the thiol-disulfide exchange chromatography assay (Fig. 4) revealed that DTT-induced thiol reduction had allowed some of these filtrate proteins (particularly spectrin) to partition into the gel-bound fraction.

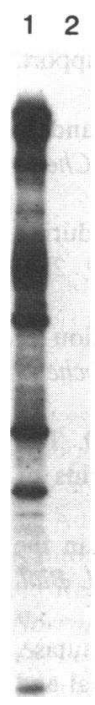

Figure 3. Apparent absence of reactive (reduced) thiols in the filtrate fraction. Proteins were labeled with $\left[{ }^{14} \mathrm{C}\right]$ iodoacetamide and applied to the gradient PAGE as described in Methods. Shown here is an autoradiograph (5-d exposure) of a two-lane slab: lane 1 carries $10 \mu \mathrm{g}$ of original, unpartitioned sickle RBC membranes (and is comparable to lane 4 of Fig. 1); and lane 2 carries $10 \mu \mathrm{g}$ of the sickle $\mathrm{RBC}$ filtrate fraction (and is comparable to lane 5 in Fig. 1).
Figure 4. DTT treatment of filtrate fraction proteins 12 allowed some of them to become gel-bound. Starting material for the experiment depicted here was a sickle RBC filtrate fraction (comparable to that shown in lane 8 of Fig. 1) with zero DTP-titratable thiols. It was treated with $10 \mathrm{mM}$ DTT (with consequent exposure of newly reduced thiols), dialyzed to remove DTT, and reapplied to the thiol-disulfide exchange chromatography assay. Despite DTT treatment, some proteins (all glycophorin and band 7; most band 4.1 and hemoglobin) continued to partition into the filtrate fraction shown in lane 1. However, some proteins (e.g., almost all bands 1, 2, 2.1, and 2.1 fragments between bands 2 and 3) were able to partition into the gel-bound fraction (lane 2), indicating that their thiols had been abnormally oxidized in the starting material. More proteolytic effect is apparent here than in Fig. 1, since this material had been subjected to twice as much handling and elapsed time. Performance of this experiment upon filtrate proteins derived from normal RBC (not shown) yielded the same qualitative result as shown here for sickle RBC.

\section{Discussion}

The possibility that RBC autooxidation could play a role in the development of sickle RBC membrane abnormalities is supported by the observation that sickle RBC spontaneously generate excessive amounts of oxygen radicals (8). Moreover, sickle RBC appear to have an abnormal membrane-associated Fenton reagent, so that pathologic generation of the particularly damaging hydroxyl radical might occur directly adjacent to crucial membrane components (8). While evidence for excessive lipid peroxidation in sickle RBC has been reported (15-17), data are incomplete regarding possible oxidative effects upon membrane proteins. Specifically, HMW aggregates with intermolecular disulfide bonds have not been detected in preparations of sickle RBC membranes (1). However, the conventional techniques heretofore applied to analysis of sickle RBC cannot detect more subtle (i.e., intramolecular) changes in thiol redox status. Consequently, we used a more sensitive technique, thiol-disulfide exchange chromatography, for analysis of sickle RBC membrane proteins.

Using this technique, which partitions individual proteins from SDS-solubilized RBC membranes on the basis of reactive thiols, we found that few proteins $(\sim 13 \%$ of the total) from normal RBC membranes partitioned into the filtrate (oxidized/ blocked-thiol) fraction. In contrast, membranes prepared from sickle RBC partitioned so that an abnormally large proportion of protein $(\sim 21 \%$ of the total) was found in the filtrate fraction. This abnormality of sickle RBC membrane proteins was simulated by treatment of normal RBC with thiol blockers and oxidants, and it was demonstrated also in membranes of $\mathrm{RBC}$ from patients with other putatively oxidative hemolytic disorders.

These results indicate abnormal intramolecular modification of protein thiols in sickle RBC membranes, since no HMW aggregates were found in membranes prepared from these cells. This abnormality appears to be due only in part to intramolecular disulfide bonds, since it could be reversed only 
partially with reducing agents. This implies existence of some further oxidation (e.g., to cysteic acid) and/or presence of other thiol modification (e.g., by dialdehyde byproducts of lipid peroxidation ["malondialdehyde"] [18]).

The absence of detectable titratable thiols in the filtrate fractions demonstrates that the technique is valid, although results do not absolutely disprove the possibility that some filtrate proteins have reduced but inaccessible thiols, thiols that remain "buried" despite boiling of membranes in SDS. On the other hand, the converse problem also exists. That is, proteins that are only partially oxidized might still bind to the assay gel, since in theory gel binding requires only a single reduced thiol per protein molecule. Thus, these results almost certainly underestimate the degree of thiol redox abnormality in sickle RBC membranes, although one cannot assume that degree of partitioning abnormality varies linearly with amount of thiol oxidation.

Qualitative analysis of membrane protein partitioning shows that most of the filtrate protein derived from normal RBC consisted of band 7 protein and glycophorin. In the latter case, this is due to the fact that glycophorin lacks constituent thiol groups (19). Although their detailed structure is not known, band 7 proteins also may lack (reduced) thiols since they resist cross-linking by disulfide-forming reagents (20) and label poorly with $\left[{ }^{3} \mathrm{H}\right]$ NEM (21). Analysis of sickle RBC membranes failed to reveal any single, particularly oxidatively vulnerable protein. Rather, the filtrate fractions were enriched with all membrane proteins, indicating generalized oxidative perturbation of the sickle RBC membrane. Of particular interest, however, is the fact that the sickle filtrates contained excessive amounts of major cytoskeletal proteins: spectrin (band 2 more than band 1), ankyrin (band 2.1), and band 4.1.

As noted in the Introduction, normality of interactions between cytoskeletal proteins may depend, in part, upon preservation of optimal thiol redox status. Hence, our findings are perhaps relevant to several sickle RBC membrane abnormalities that may reflect cytoskeletal dysfunction. First, these data may help explain the fixed membrane conformation of irreversibly sickled cells (22), which is currently hypothesized to reflect abnormal interactions between cytoskeletal proteins (1). This could be due to alteration of tertiary structure due to abnormal thiol oxidation, as has been reported preliminarily for certain patients with hereditary spherocytosis (23). Second, since thiol modification with NEM adversely affects spectrin/ ankyrin interactions (3), our data may explain why inside-out vesicles prepared from sickle $\mathrm{RBC}$ fail to bind spectrin normally (an ankyrin-dependent process) (24). Third, since thiol oxidants destabilize the normal asymmetry of RBC membrane phospholipids (21), these data may help explain the partial loss of phospholipid asymmetry in irreversibly sickled cells (25). Finally, recent data suggest that cytoskeletal thiol oxidation perturbs normal permeability barriers (26), which may be relevant to the abnormal cation homeostasis of sickle RBC.

It is interesting to note that our two sickle patients with the least and most abnormal partitioning abnormality had the lowest and greatest apparent hemolytic rates, respectively, as evidenced by hematologic parameters and propensity for RBC adherence to macrophages (17). However, the number of patients studied to date is insufficient for us to unequivocally identify any relationship between degree of thiol oxidation abnormality and either hemolytic or vasocclusive clinical severity. Nevertheless, these observations generally support the concept that RBC autooxidation may play a role in the pathophysiology of sickle disease.

\section{Acknowledgments}

We thank W. Foker, B. Burhans, and M. Balasingam for technical assistance and Dr. Bo Hedlund for helpful discussions.

This work was supported by the National Institutes of Health (grants HL26139 and HL30160, and a Research Career Development Award to Dr. Hebbel), the Twin Cities Sickle Cell Anemia Research Corporation, and the Minnesota Medical Foundation.

\section{References}

1. Palek, J., and S. E. Lux. 1983. Red cell membrane skeletal defects and hereditary and acquired hemolytic anemias. Semin. Hematol. 20:189-224.

2. Smith, D. K., and J. Palek. 1983. Sulfhydryl reagents induce altered spectrin self-association, skeletal instability, and increased thermal sensitivity of red cells. Blood. 62:1190-1196.

3. Bennett, V. 1978. Purification of an active proteolytic fragment of the membrane attachment site for human erythrocyte spectrin. $J$. Biol. Chem. 253:2292-2299.

4. Wolfe, L. C., K. M. John, J. C. Falcone, A. M. Byrne, and S. E. Lux. 1982. A genetic defect in the binding of protein 4.1 to spectrin in a kindred with hereditary spherocytosis. N. Engl. J. Med. 307:1367-1374.

5. Flynn, T. P., D. W. Allen, G. J. Johnson, and J. G. White. 1983. Oxidant damage of the lipids and proteins of the erythrocyte membranes in unstable hemoglobin disease. J. Clin. Invest. 71:12151223.

6. Johnson, G. J., D. W. Allen, T. P. Flynn, B. Finkel, and J. G. White. 1980. Decreased survival in vivo of diamide incubated dog erythrocytes. J. Clin. Invest. 66:955-961.

7. Johnson, G. J., D. W. Allen, S. Cadman, V. Fairbanks, J. G. White, B. C. Lampkin, and M. E. Kaplan. 1979. Red cell membrane polypeptide aggregates in glucose-6-phosphate dehydrogenase mutants with chronic hemolytic disease. $N$. Engl. J. Med. 301:522-527.

8. Hebbel, R. P., J. W. Eaton, M. Balasingam, and M. H. Steinberg. 1982. Spontaneous oxygen radical generation by sickle erythrocytes. $J$. Clin. Invest. 70:1253-1259.

9. Egorov, T. A., A. Svenson, L. Ryden, and J. Carlsson. 1975. A rapid and specific method for isolation of thiol-containing peptides from large proteins by thiol-disulfide exchange on a solid support. Proc. Natl. Acad. Sci. USA. 72:3029-3033.

10. Lowry, O. H., N. J. Rosebrough, A. L. Farr, and R. J. Randall. 1951. Protein measurement with folin phenol reagent. J. Biol. Chem. 193:265-275.

11. Laemmli, U. K. 1970. Cleavage of structural proteins during the assembly of the head of bacteriophage T4. Nature (Lond.). 227: 680-685.

12. Grassetti, D. R., and J. F. Murray. 1967. Determination of sulfhydryl groups with 2,2'- or 4,4'-dithiodipyridine. Arch. Biochem. Biophys. 119:41-49.

13. Siegel, D. L., S. R. Goodman, and D. Branton. 1980. The effect of endogenous proteases on the spectrin binding proteins of human erythrocytes. Biochim. Biophys. Acta. 598:517-527.

14. Rao, A. 1979. Disposition of the Band 3 polypeptide in the human erythrocyte membrane: the reactive sulfhydryl groups. J. Biol. Chem. 254:3503-3511.

15. Das, S. K., and R. C. Nair. 1980. Superoxide dismutase, glutathione peroxidase, catalase and lipid peroxidation of normal and sickled erythrocytes. Br. J. Haematol. 44:87-92. 
16. Jain, S. K., and S. B. Shohet. 1984. A novel phospholipid in irreversibly sickled cells: evidence for in vivo peroxidative membrane damage in sickle cell disease. Blood. 63:362-367.

17. Hebbel, R. P., and W. J. Miller. 1984. Phagocytosis of sickle erythrocytes: immunologic and oxidative determinants of hemolytic anemia. Blood. 64:733-741.

18. Buttkus, H. 1969. Reaction of cysteine and methionine with malonaldehyde. J. Am. Oil Chem. Soc. 46:88-93.

19. Tomita M., H. Furthmayr, and V. T. Marchesi. 1978. Primary structure of human erythrocyte glycophorin A. Isolation and characterization of peptides and complete amino acid sequence. Biochemistry. 17:4756-4770.

20. Wang, K., and F. M. Richards. 1974. An approach to nearest neighbor analysis of membrane proteins. J. Biol. Chem. 249:80058018.

21. Haest, C. W. M., G. Plasa, D. Kamp, and B. Deuticke. 1978. Spectrin as a stabilizer of the phospholipid asymmetry in the human erythrocyte membrane. Biochim. Biophys. Acta. 509:21-32.
22. Lux, S. E., K. M. John, and M. J. Karnovsky. 1976. Irreversible deformation of the spectrin-actin lattice in irreversibly sickled cells. $J$. Clin. Invest. 58:955-963.

23. Becker, P. S., S. Donner, and S. E. Lux. 1983. Evidence for a defect in spectrin thiols in the type of hereditary spherocytosis associated with defective spectrin-4.1 binding (HS[Sp-4.1]). Blood. 62:43a. (Abstr.)

24. Platt, O. S., J. France, and S. E. Lux. 1982. Demonstration of a molecular defect in the membrane skeleton of sickle cells: diminished binding of spectrin to sickle inside-out vesicles (IOV). Blood. 60:48a. (Abstr.)

25. Lubin, B., D. Chiu, J. Bastacky, B. Roelofsen, and L. L. M. Van Deenen. 1981. Abnormalities in membrane phospholipid organization in sickled erythrocytes. J. Clin. Invest. 67:1643-1649.

26. Deuticke, B., B. Poser, P. Lutkemeier, and C. W. M. Haest. 1983. Formation of aqueous pores in the human erythrocyte membrane after oxidative cross-linking of spectrin by diamide. Biochim. Biophys. Acta. 731:196-210. 